Schäfer, A.I. ; Broeckmann, A. ; Richards, B.S. (2007) Renewable energy powered membrane technology. 1. Development and characterisation of a photovoltaic hybrid membrane system, Environmental Science \& Technology, 41, 998-1003.

DOI: $10.1021 / \mathrm{es} 061166 \mathrm{o}$

\section{Renewable energy powered membrane technology. 1. Development and characterisation of a photovoltaic hybrid membrane system}

\author{
A.I. Schäfer ${ }^{1,2^{*}}$, A. Broeckmann ${ }^{1}$, B.S. Richards ${ }^{3,4}$ \\ ${ }^{1}$ Environmental Engineering, University of Wollongong, \\ Wollongong NSW 2522, Australia \\ ${ }^{2}$ School of Engineering and Electronics, The University of Edinburgh, \\ Edinburgh, EH9 3JL, United Kingdom \\ ${ }^{3}$ Centre for Sustainable Energy Systems, Australian National University, \\ Canberra, ACT 0200, Australia \\ ${ }^{4}$ School of Engineering and Physical Sciences, Heriot-Watt University,
} Edinburgh, EH14 4AS, United Kingdom

Submitted to

Environmental Science and Technology

June 2006

resubmitted November 2006

\section{Abstract}

In isolated communities where potable water sources as well as energy grids are limited or nonexistent, treating brackish groundwater aquifers with small-scale desalination systems is an interesting and sometimes viable alternative to existing water infrastructures. With regards to the performance of intermittently operated desalination systems only very limited experience exists, both with regards to efficiency as well as water quality. Therefore, these experiments were conducted with a constant power source as a step towards defining a safe operating window, and provide a basis for inter were peeforme with photovoltaic-powered membrane filtration (PV-membrane) systen. Four nanofltration and reverse osmosis membranes (BW30, ESPA4, NF90, TFC-S) and a number of operation parameter combinations (transmembrane pressure, feed flow, membrane choice) were investigated to find the best operating conditions for maximum drinking water production and minimum specific energy consumption (SEC). The ESPA4 membrane performed best for this brackish source, producing $250 \mathrm{~L} / \mathrm{h}$ of good drinking water $(257 \mathrm{mg} / \mathrm{L}$ TDS; $400 \mu \mathrm{S} / \mathrm{cm})$ at an SEC of $1.2 \mathrm{kWh} / \mathrm{m}^{3}$. The issue of brine disposal or reuse is also discussed and the article compares the salinity of the produced brine with livestock water. Since the feed water is bacteria and most viuses and hence can be seen more as a reusable product stream than a won stream with a disposal problem.

Keywords

Nanofiltration, reverse osmosis, membranes, solar energy, photovoltaic, brackish groundwater treatment, remote communities, international development, small-scale desalination system. 
Schäfer, A.I. ; Broeckmann, A. ; Richards, B.S. (2007) Renewable energy powered membrane technology. 1. Development and characterisation of a photovoltaic hybrid membrane system, Environmental Science \& Technology, 41, 998-1003.

\section{Introduction}

Water provision for remote communities is a critical issue as a vast number of lives are los annually due to lack of access to safe drinking water (1). The availability of electricity networks in remote areas, however, is often as limited as the availability of safe drinking water, and technologies that are able to remove dissolved contaminants require substantial amounts of energy.

For arid countries that experience minimal rainfall and hence limited freshwater availability, a synergy often exists with the abundance of solar radiation received at such locations (2). Fortunately, such a relationship does not apply to the availability of groundwater in such regions. The situation described above, closely matches that of Australia, where the majority of the rainfall occurs along the coastline, compared to $200-300 \mathrm{~mm}$ annual rainfall in Central and Western Australia (3). However, Central Australia receives a daily average of at least 6.7 hours of full sunshine $\left(\mathrm{kW} / \mathrm{m}^{2}\right), 20-50 \%$ more than is received along the wetter coastline (4). While this climate reflects very strongly in the country's population distribution, a large fraction of Centra Australia is farmland or home to indigenous communities that often rely on poor water resources, with many commlnities being too small to have controlled and monitored water supplies. Dince with many comr water is generally supplied from groundwater bores, which are of varying quality ranging from drinkable water to inconsumable brackish water.

For remote communities that possess a brackish groundwater resource, a small desalination system can avoid the health problems associated with drinking high salinity groundwater $(5,6)$ and is a sustainable alternative to trucking water in to remote locations. While desalination can be relatively energy-intensive technology, such a system can be powered from photovoltaic panels, converting the abundant sunshine into direct-current electricity. In developing countries, the role of such a system would be to provide safe drinking water where previously only contaminated surface water was available.

The system described here combines advanced water treatment technology (membrane processes) with solar electric energy (photovoltaics) and is autonomous in that it requires no other infrastructure than a water source. The system provides about $1000 \mathrm{~L}$ of drinking water per (solar) day for remote communities with $50-100$ people, however because both PV modules and membranes are modular technologies the size could be scaled up or down. In contrast to other systems no batteries are used and in consequence power fluctuates

Several photovoltaic-powered membrane filtration (PV-membrane) systems have been developed in the past (2,5,7-15). The performance of such systems is best evaluated via water productivity and power consumption, for which the specific energy consumption (SEC, unit: $\mathrm{kWh} / \mathrm{m}^{3}$ ) the accepted figure of merit. A system with a greater power consumption and lower water productivity will De SEC of a PVmembrane unit needs to be as low as possible, since energy costs have been reported as comprising about half of the capital costs of a system $(8,9)$. It is important to differentiate between the energy consumption of seawater and brackish water PV-membrane system because the SEC is strongly dependent on salinity (9). The SEC is further affected by parasitic power losses within the PVmembrane system. For the PV-membrane system described here, there are small losses within the maximum power point tracking (MPPT) electronics that optimise the PV array output to achieve the best pump performance. However, for other PV-membrane systems that include batteries, a DC$\mathrm{AC}$ inverter, and $\mathrm{AC}$ pumps, the electrical losses could be in the order of $30-40 \%$

The SECs of seawater PV-membrane systems ranges from $4 \mathrm{kWh} / \mathrm{m}^{3}$ with energy recovery (10) to 15 $15 \mathrm{kWh} / \mathrm{m}^{3}$-membrane systems ranges from $>15 \mathrm{kWh} / \mathrm{m}^{3}$ without energy recovery $(11,12)$. The groundwater salinity in the majority of communities is typically far less than seawater. It is interesting to investigate the potential of such
"brackish" PV-membrane systems as the reduced feedwater salinity can result in significant energy savings, thus making such a technology more economically viable. The SECs of brackish PVmembrane systems vary greatly with size, salinity and appropriate membrane choice and range from $1.2 \mathrm{kWh} / \mathrm{m}^{3}$ (5) to $26 \mathrm{kWh} / \mathrm{m}^{3}(13)$

The aim of this paper is the evaluation of PV-membrane system performance such as water productivity, salt retention and SEC at a Central Australian bore with relatively poor water quality by testing four commercial membranes. For systems operated directly from PV electricity, the output power at a particular location will vary depending on time of day, cloud cover, and output power at a plicher, and temperatue. This fuctuation affects the punp perfomn vary, inevitably influencing membrane performance. The performance tests carried out in this research aim to establish a safe operating window within which the system can operate autonomously and to achieve this in a systematic and controlled manner, the system is operated using a generator at flow and pressure values in the equivalent range of those obtained with PV electricity. A subsequent paper in this series will present results obtained at operation with naturally fluctuating power.

\section{Materials and Methods}

\subsection{System Characteristics}

The reverse osmosis solar desalination system (PV-membrane) described here is a two-stage membrane system powered by PV. The unit, now in its fifth prototype development stage (16), is mounted on a 4WD double-axis trailer (see Figure 3), which allows the system to be transported to isolated locations for testing. During travelling, the PV panels pivot to form a roof and the trailer is then covered with a waterproof canvas tarpaulin and sealed against the environment.

[Figure 1]

The four $24 \mathrm{~V}_{\mathrm{DC}}$ (nominal) PV modules (BP Solar, BP3150S) each provide a maximum power of $150 \mathrm{~W}$. The system pump is rated at a maximum power of $300 \mathrm{~W}$ and therefore only two PV modules are required to power the pump, while the other two modules can be used to power auxiliary equipment. The PV panels are mounted onto a single-axis solar tracker (Mono-Pumps Australia) that is guided by a global positioning system. The tracker automatically follows the path of the sun from east to west during the day. The zenith angle of the panels is manually adjusted, such that the zenith angle equals the local latitude for optimum year-round performance ( $24^{\circ}$ for this work). The azimuth angle is permanently tilted to true north in the southern hemisphere.

The system can also be powered from a backup generator (Honda Eu10i $1 \mathrm{kVA}$ ) or $240 \mathrm{~V}_{\mathrm{AC}}$ grid power for determining system performance with a constant power supply, as was done for the testing presented in this paper. A 200 Ah capacity $12 \mathrm{~V}_{\mathrm{DC}}$ battery bank and battery charger are used only to power peripheral research equipment (such as data acquisition and analysis instrumentation, and a laptop computer)

A custom-designed progressive cavity pump (Mono-Pumps Australia), especially designed to run of solar power, is installed between the first and second membrane stage. The majority of the wetted parts in the system are made from stainless steel. A schematic of the system is shown in Figure 2.

[Figure 2] 
Schäfer, A.I. ; Broeckmann, A. ; Richards, B.S. (2007) Renewable energy powered membrane technology. 1. Development and characterisation of a photovoltaic hybrid membrane system, Environmental Science \& Technology, 41, 998-1003.

The first filtration stage consists of six Zenon ZW10 ultrafiltration membranes connected in parallel and immersed in a $300 \mathrm{~L}$ stainless steel tank. Additionally, an air blower (Nitto LA80a) can be used for gentle air bubbling of the hollow fibre membranes from the outside and assist with removal of membrane deposits. In the experiments performed here, air bubbling was used in the feed tank prior to sampling for 10 mins every hour. The purpose of this air bubbling was more to ensure homogeneous mixing rather than fouling prevention. The pump is drawing feed water through the UF membra with up to 12 bar. Four with up to 12 bar. Four different 4 inch membrane modules are tested (salt retention and membrane surface area as provided by manufacturers in brackets); namely TFC-S (Koch Membrane Systems, $85 \%, 7.2 \mathrm{~m}^{2}$ ), NF90 (Filmtec, 95\%, $6.7 \mathrm{~m}^{2}$ ), ESPA4 (Hydranautics, 99.2\%, $7.9 \mathrm{~m}^{2}$ ), and BW30 (Filmtec, $99.5 \%, 7.6 \mathrm{~m}^{2}$ ).

Several sensors monitor important operating parameters during the experiments (see Figure 2). The power requirements are monitored by measuring pump voltage and pump current or directly from the electronic interface of the pump. Pressure sensors (Bürkert 8323, labelled P1-3 in Figure 2) are located on either side of the pump and after the NF/RO vessel on the concentrate side. Flow sensor record feed (Bürkert 8035) and concentrate (S8011R Flow Transducer, Farnell Type 178-923) flows. When the flow is outse the operting range of the sents, volume cylinders (2L) and flows. When the flow is outside the operating range of the sensors, volumetric cylinders ( $2 \mathrm{~L}$ ) and stopwatches have been un conductivity and temperature are also monitored (WTW MultiLine P4) for the feed, permeate and concentrate stream. All of these parameters are measured at $5 \mathrm{~s}$ intervals using a datalogger (DataTaker DT500) and are downloaded to a laptop. Regular sampling of process streams occurred at $0.5-1 \mathrm{~h}$ intervals throughout the experiments for further water analyses.

\subsection{Experimental Design}

To determine the safe operating window, the system is setup to recycle permeate and concentrate into the feed tank, as can be seen in Figure 2. In addition, the generator is used to provide a constant power supply to the system in order to evaluate effects of pressure and flow on membrane performance in a systematic manner. For each membrane, pressure is varied from $4-12$ bar and feed flow set at 300,400 and $500 \mathrm{~L} / \mathrm{h}$. This range reflects the limits of the system with this peed flow set at 300,400 and $500 \mathrm{~L} / \mathrm{h}$. This range reflects the limits of the system with this particular water source operated with PV electricity, with no permeate being produced at pressures below 4 bar due to osmotic pressure limitations. At each operation point steady state is reached, recorded at steady state and membrane specific parameters calculated using the following relationships

$$
\begin{array}{ll}
\text { Transmembrane pressure } & \text { TMP }=\frac{\left(p_{3}-p_{2}\right)}{2}-p_{\text {Permeate }}=\frac{\left(p_{3}-p_{2}\right)}{2}, \\
\text { Recovery } & Y=\left(\frac{Q_{\text {Permeate }}}{Q_{\text {Feed }}}\right) \cdot 100 \%, \\
\text { Retention } & R=\left(1-\frac{C_{\text {Permeate }}}{C_{\text {Feed }}}\right) \cdot 100 \%, \\
\text { Flux } & J=\left(\frac{Q_{\text {Permeate }}}{A_{\text {Membrane }}}\right),
\end{array}
$$

$$
\text { Specific energy consumption } \quad \mathrm{SEC}=\left(\frac{I_{P_{\text {Pump }}} \cdot U_{P_{\text {Pump }}}}{Q_{\text {Permeate }}}\right) \text {, and }
$$

Total dissolved solids

$$
\mathrm{TDS}=k \cdot E C,
$$

where, TMP the transmembrane pressure (bar), $p$ is relative pressure (bar; where $p_{\text {Permeate }}=0$ ), $Y$ the recovery, $J$ is flux $\left(\mathrm{L} / \mathrm{m}^{2} \cdot \mathrm{h}\right), Q$ the flow $(\mathrm{L} / \mathrm{h}), A$ is area $\left(\mathrm{m}^{2}\right), R$ is retention $(\%), C$ is the concentration $(\mathrm{mg} / \mathrm{L}), I$ is current (A), $U$ the voltage (V), TDS is total dissolved solids concentration $(\mathrm{mg} / \mathrm{L})$, and $E C$ is electrical conductivity $(\mu \mathrm{S} / \mathrm{cm}) . E C$ is converted into total dissolved solids (TDS) using a conversion factor $k=0.64$ for Australian groundwater with high sodium content (17). (TDS) using a conversion factor $k=0.64$ for Australian groundwater with high sodium content (17).
It should be noted here that this conversion is strictly speaking feedwater dependent and varies for It should be noted here that this conversion is strictly speaking feedwater dependent and varies fo each process stream. A maximum TDS of $500 \mathrm{mg} / \mathrm{L}$ for drinking water then correlates to $780 \mu \mathrm{S} / \mathrm{cm}$, which is the Australian Drinking Water Guideline (ADWG) value (18). It should be noted here that this drinking water quality guideline value may be too low for remote communities in Australia where preference of some locals is towards drinking water that is somewhat saltier than the suggested $500 \mathrm{mg} / \mathrm{L}$ guideline.

\subsection{Bore Water Location and Characteristics}

Testing was performed on a bore at Pine Hill Station (bore number RN13693), a cattle farm located $\sim 140 \mathrm{~km}$ north-west of Alice Springs in the Northern Territory of Australia. Werner and Schäfer (19) have described the context of this 'cattle farm' in detail. The bore chosen for these studies is of high salinity and trace contaminant content. Water quality is tested when a new bore is installed, although no regular monitoring is performed. While it is unlikely that drinking water needs to be produced from this source at Pine Hill, the bore was chosen due to its poor water characteristics for a worst case scenario for the system. A water analysis with selected values is presented in Table 1 together with a summary of the ADWG (18).

\section{[Table 1]}

The removal of trace contaminants such as uranium and arsenic will be presented in a subsequent paper in this series together with results of the full chemical analysis of various water samples. The fluctuation of trace contaminant removal as a function of energy variation as well as solution fluctuation of trace contaminant removal as a function of energy variation as
chemistry is indeed interesting and important for such non-steady state operations.

\section{Results and Discussion}

The determination of the safe operating window of the system where both water quantity and quality can be maintained at an acceptable SEC is the main aim of this study. While the power supplied to the system was stable during the experiments, varying the flow and pressure isnecessary to determine the upper and lower operating boundaries. This characterisation is important for the interpretation of results from operation with the solar panels which will be presented in a subsequent paper. The difficulty of solar operation is the simultaneous variation of several operation parameters which makes scientific conclusions difficult to justify without thorough characterisation of the system.

Water productivity (or flux) is the first measure of this operating window and results are plotted in the left of Figure 3 as permeate flux versus the applied transmembrane pressure (TMP) for varying 
Schäfer, A.I. ; Broeckmann, A. ; Richards, B.S. (2007) Renewable energy powered membrane technology. 1. Development and characterisation of a photovoltaic hybrid membrane system, Environmental Science \& Technology, 41, 998-1003.

feed flows $\left(Q_{F e e d}\right)$ and four different membranes (BW30, ESPA4, NF90, TFC-S). In general, flux increases linearly with the applied driving force, namely pressure. At high transmembrane pressure, a departure from this linear relationship occurs due to concentration polarisation effects. These effects are caused by low tangential flow across the membrane (low $Q_{F e e d}$ ) due to the high flow through the membrane (high $J$ ) arising from the high TMP. This is improved when the feed flow is increased in which case crossflow is enhanced, and the boundary layer thickness and hence concentration polaision decreased. This effect is least pronounced for the TFC-S membrane, concenterane, primarily because of lower salt retention or this membrane. In other words, the performance limiting non-linear effects are the result of the system being operated at a too high a recovery. The productivity of the membranes is ESPA4 > TFC-S > NF90 > BW30 and as further results will show there are reasons for this order.

[Figure 3]

Recovery can be interpreted as system efficiency regarding the flow, and also indirectly expresses how much concentrate is produced. Recovery decreases as $Q_{\text {Feed }}$ increases due to a larger proportion of water being pumped tangential to the membrane than across compared to smaller flow, an varied from 5 to $70 \%$ (see right hand side of Figure 3). The recovery is inevitably a result of set $Q_{F}$ and TMP as well as intrinsic membrane permeability and water chacteristics. The syste performance is investigated over a wide range of operating conditions due to the fact that pressure and flow will vary as a result of fluctuating power, but recovery will further influence the amount of water and RO concentrate produced. It was the initial concept of this system to be able to set recovery in accordance with local water requirements and hence produce only the required fraction of drinking water. Hence the concentrate quality is better and subsequent discharge issues are reduced or resolved by using the water for non-drinking purposes.

\section{[Figure 4]}

Concentration polarisation, as well as related diffusion and convection phenomena, affect permeate quality. For this reason the conductivity of feed, permeate and concentrate was monitored and retention calculated. Membrane characteristics further a Figure 4, the results for permeate conductivity and retention are shown, respectively. The EC of the feed water was measured (in average over all tests) to be $8290 \mu \mathrm{S} / \mathrm{cm}(5300 \mathrm{mg} / \mathrm{L}$ as TDS). The horizontal line in Figure 4 (left) is the AWQG limit (500 mg/L TDS; $780 \mu \mathrm{S} / \mathrm{cm}$ ), while in Figure 4 (right) it represents the retention required for the product water. These targets are achieved for the BW30 membrane for the entire pressure and flow range investigated, the ESPA4 membrane fo pressures between 6 and 10 bar (high pressure and low flow compromise permeate quality), the TFC-S membrane is $70-85 \%$, which is not sufficient for this water.

[Figure 5]

The SEC is what ultimately determines the cost of the system as energy requirements translate into required solar panel area and water productivity into membrane area. The variation of the SEC at different TMPs is plotted in Figure 5. Despite less energy being required at low pressures, the SEC values are high in this range as very little permeate is produced. The higher the retention also increases SEC due to the osmotic pressure build-up. Higher $Q_{\text {Feed }}$ results in an increased SEC, as additional energy is needed for pumping. This difference diminishes at higher pressures (TMP $>$ 6 bar) and the SEC values remain relatively constant in the upper pressure range. This indicates that at moderate to high pressures the improved flux due to higher crosflow velocities outweigh the that at moderate to high pressures the improved flux due to higher crossflow velocities outweigh the extra energy required for pumping. Minimum SEC values are; $1.8 \mathrm{kWh} / \mathrm{m}^{3}$ for BW30 (11 bar $400 \mathrm{~L} / \mathrm{h}) ; 1.1 \mathrm{kWh} / \mathrm{m}^{3}$ for ESPA4 $(10 \mathrm{bar}, 300 \mathrm{~L} / \mathrm{h}) ; 1.4 \mathrm{kWh} / \mathrm{m}^{3}$ for NF90 $(9 \mathrm{bar}, 300 \mathrm{~L} / \mathrm{h})$; and
$1.1 \mathrm{kWh} / \mathrm{m}^{3}$ for TFC-S (10 bar, $\left.300 \mathrm{~L} / \mathrm{h}\right)$.
It is difficult to make a detailed comparison of those results with published data as the majority of brackish PV-membrane systems have been tested on feedwaters in the salinity range of $1590-5000$ $\mu \mathrm{S} / \mathrm{cm}(5,13,14,20)$, which are significantly lower than that encountered here $(8290 \mu \mathrm{S} / \mathrm{cm})$. The significant dependence of SEC on the salinity is demonstrated by Richards et al. where an SEC of $5.5 \mathrm{kWh} / \mathrm{m}^{3}$ at a feed salinity of $1000 \mathrm{mg} / \mathrm{L}(1560 \mu \mathrm{S} / \mathrm{cm})$ was achieved, rising to $9.4 \mathrm{kWh} / \mathrm{m}^{3}$ and $26 \mathrm{kWh} / \mathrm{m}^{3}$ for $3000 \mathrm{mg} / \mathrm{L}(4690 \mu \mathrm{S} / \mathrm{cm})$ and $7500 \mathrm{mg} / \mathrm{L}(11720 \mu \mathrm{S} / \mathrm{cm})$, respectively $(7,15)$. In addition, smaller systems tend to operate less efficiently, as evidenced by a PV-membrane system tested in Portugal with brackish water $(2000-5000 \mu \mathrm{S} / \mathrm{cm})$ that had a SEC of nearly $26 \mathrm{kWh} / \mathrm{m}^{3}$ (13). A larger $\left(5.0-7.5 \mathrm{~m}^{3} / \mathrm{day}\right) \mathrm{PV}$-membrane system that has been treating brackish water $(1850 \mu \mathrm{S} / \mathrm{cm})$ for an extended period in Oman has an estimated SEC of $2.3 \mathrm{kWh} / \mathrm{m}^{3}$ (14). The SEC of the only commercially-produced brackish PV-membrane system has been reported as being of $12 \mathrm{kWh} / \mathrm{m}^{3}$ during treatment testing of brackish $(2180 \mu \mathrm{S} / \mathrm{cm})$ water (5). The benefits of syst optimisation and up-scaling are demonstrated by examining the performance of earlier prototypes of he PV-membrane system reported here, which achieved an SEC of a $8 \mathrm{kWh} / \mathrm{m}^{3}(3500 \mathrm{mg} / \mathrm{L}$ TDS when producing $250 \mathrm{~L} /$ day with a 2 inch membrane (2) and an SEC of $2.2 \mathrm{kWh} / \mathrm{m}^{3}(5000 \mathrm{mg} / \mathrm{L}$ TDS) for a $1000 \mathrm{~L} /$ day unit with a 4 inch module (7). Choosing the right membrane for a given feed water quality is also very important and a reduction of the SEC of up to $70 \%$ has been demonstrated (7). In general it can be said that the SEC of the PV-membrane system with the ESPA4 membrane is very good for this water source.

Another important criterion for system implementation is the concentrate stream. In this system, all water is pretreated with UF and is hence physically disinfected (21). In large-scale desalination (1) environmental problems due to the density of the waste stream being higher than the feed wate $(22,23)$, or requires further treatment $(24,25)$. In small-scale plants the concentrate may be introduced into the sewer system, if available. Another common consideration is the option of reintroducing the concentrate into the groundwater. This is questionable, particularly if chemicals, such as antiscalants, have been added. In Central Australia, the opportunity exists to use the concentrate for other household applications or as stock water. The possibility for such secondary usage of the concentrate depends on the raw water quality, system recovery and the requirements for the secondary grade water. Concentrate EC is illustrated in the right hand side of Figure 5 in comparison with the requirements to maintain condition of livestock (sheep $(21800 \mu \mathrm{S} / \mathrm{cm})$ and beef cattle $(8800 \mu \mathrm{S} / \mathrm{cm})(26)$. Note that the tolerance for healthy growth is $6700 \mu \mathrm{S} / \mathrm{cm}$ and 10 $000 \mu \mathrm{S} / \mathrm{cm}$ for beef cattle and sheep, respectively. It is important in this case that the raw water quality of this bore is poor $(8290 \mu \mathrm{S} / \mathrm{cm})$, which is already higher than the suggested limit for healthy growth for beef cattle (which is the current usage of this bore water), but the concentrate remains at a level below the limit for sheep to maintain condition and hence can be used for this purpose. However, the impact of such longer term water dispersion on soil salinity remains to be investigated.

In summary, the conducted field trial has demonstrated good and stable performance of the system as a potable water supply for isolated communities in Central Australia. Desalinated brackish groundwater from aquifers can be used to provide those people with drinking water. The performance of the PV-membrane system under a wide range operating modes has been presented in this article. The membrane choice has a significant influence on the system output. It was concluded that for this specific test site with highly brackish feedwater, the ESPA4 membrane is the best choice. For maximum drinking water production, the system should run at high transmembrane pressure and high cross flow velocities. Other membranes were able to produce better quality water but with higher energy demand (BW30, NF90), whereas one membrane has not been able to fulfil the recommended drinking water guidelines (TFC-S). The system SEC is equal or lower to other systems that are operated with energy recovery which is an excellent performance result, in particular seeing the higher salinity of this water. 
Schäfer, A.I. ; Broeckmann, A. ; Richards, B.S. (2007) Renewable energy powered membrane technology. 1. Development and characterisation of a photovoltaic hybrid membrane system, Environmental Science \& Technology, 41, 998-1003.

DOI: $10.1021 / \mathrm{es} 0611660$

\section{Acknowledgements}

The project is funded through the Australian Research Council Linkage Project LP0349322 in collaboration with Mono Pumps Australia while a 2005 Mondialogo Award (UNESCO/DaimlerChrysler Partnership) has funded the project implementation stage through the field trial. John Childs (Northern Territory Power and Water; CRC Desert Knowledge) is acknowledged for his support with bore water quality data and dest logistics for the field is acknowledged The authors would like to thank Gil Bowman (Pine Hill Staton) for his hospitality and insightfu discussions, as well as the field trial sponsors BP Solar (Australia), GHD Pty. Ltd. (Water Group, Brisbane), Department of Environment and Heritage, New South Wales Department of Commerce, and the Australian National University. A very special thank you goes to the students who participated in the field trial; Kai Ratte, Melanie Werner, Thomas Kruttschnitt and Philipp Sausele.

\section{References}

(1) World Health Organisation (WHO) "Guidelines for Drinking Water Quality. Vol. 1:

Recommendations.," WHO, 1993

(2) Richards, B. S.; Schäfer, A. I. Photovoltaic-powered desalination system for remote Australian

communities; Renewable Energy 2003, 28, 2013-2022.

(3) Australian Bureau of Meteorology, 2006.

4) Lee, T.; Oppenheim, D.; Williamson, T. Australian Solar Data Radiation Handbook (ASDRH);

Energy Resource Development Council: Sydney, Australia, 1995.

(5) Mathew, K.; Dallas, S.; Ho, G.; Anda, M. In Australia and New Zealand Solar Energy Societ

Conference: Solar 99: Geelong, Vic, Australia, 1999

(6) National Health \& Medical Research Council (NHMRC) "Promoting the Health of Aboriginal and

Torres Strait Island Communities," 1996

(7) Masson, L.; Richards, B. S.; Schäfer, A. I. System design and performance testing of a hybrid

membrane photovoltaic desalination system; Desalination 2005, 179, 51-59

(8) Alawaji, S. H.; Smiai, M. S.; Rafique, S.; Stafford, B. PV-powered water pumping and desalination

plant for remote areas in Saudi Arabia; Applied Energy 1995, 52, 283-289.

(9) Laborde, H. M.; Franca, K. B.; Neff, H.; Lima, A. M. N. Optimization strategy for a small-scale

reverse osmosis water desalination system based on solar energy; Desalination 2001, 133, 1-12.

(10) Keefer, B. G.; Hembree, R. D.; Schrack, F. C. Optimized matching of solar photovoltaic power with

reverse osmosis desalination; Desalination 1985, 54, 89-103.

(11) Herold, D.; Horstmann, V.; Neskakis, A.; Plettner-Marliani, J.; Piernavieja, G.; Calero, R. Small scale photovoltaic desalination for rural water supply - demonstration plant in Gran Canaria; Renewable Energy 1998, 14, 293-298.

(12) Herold, D.; Neskakis, A. A small scale PV-driven reverse osmosis desalination plant on the island of Gran Canaria; Desalination 2001, 137, 285-292.

(13) Joyce, A.; Loureiro, D.; Rodrigues, C.; Castro, S. Small reverse osmosis units using PV systems for water purifications in rural places; Desalination 2001, 137, 39-44.

(14) Al Suleimani, Z.; Rajendran Nair, V. Desalination by solar-powered reverse osmosis in a remote

area of the Sultanate of Oman; Applied Energy 2000, 65, 367-380.

(15) Richards, B. S.; Remy, C.; Schäfer, A. I. In Proc of 19th European Photovoltaic Solar Energy

Conference: Paris, France, 2004; pp 3369-3372.

(16) Schäfer, A. I.; Richards, B. S. From Concept to Commercialisation: Student Learning in a

Sustainable Engineering Innovation Project; European Journal of Engineering Education 2006, (in press).

(17) McNeil, V. H.; Cox, M. E. Relationship between conductivity and analysed composition in a large set of natural surface-water samples, Queensland, Australia; Environmental Geology 2000, 29, 1325-1333. (18) National Health and Medical Research Council (NHMRC) "Australian Drinking Water Guidelines, National Health and Medical Research Council, National Water Quality Management Strategy, 2004.

(19) Werner, M.; Schäfer, A. I. Social aspects of a solar-powered desalination unit for remote Australian communities: Desalination 2007, 203, 375-393.
(20) Badreddin, E.; Gambier, A.; Aboul-Fotouh, F. Laboratory set-up for education and research on automation of reverse osmosis plants employing a sustainable energy source; Desalination 2004, 166, $307-$ 314 .

(21) Côté, P.; Cadera, J.; Coburn, J.; Munro, A. A new immersed membrane for prestreatment for reverse osmosis; Desalination 2001, 139, 229-236.

(22) Einav, R.; Harussi, K.; Perry, D. The footprint of the desalination processes on the environmen

Desalination 2002, 152, 141-154.

(23) Del Bene, J. V.; Jirka, G.; Largier, J. Ocean brine disposal; Desalination 1994, 97, 365-372.

(24) Awerbuch, L.; Weekes, M. C. Disposal of concentrates from brackish water desalting plants by

means of evaporation technology; Desalination 1990, 78, 71-76.

(25) Squire, D. Reverse osmosis concentrate disposal in the UK; Desalination 2000, 132, 47-54.

(26) Department of Water, L. a. B. C. "Fact Sheet 32: Salinity of Groundwater in South Australia,"

Government of South Australia, 2005.

\section{List of Figures}

Figure 1 Photo of the trailer-mounted PV-membrane system during field trials in Central Australia. The trailer has ballast tanks and retractable legs to facilitate operation under high wind conditions.

Figure 2 Schematic diagram of the water flows (solid lines) and electrical connections (dotted lines) for the components of the PV-membrane system: submerged UF membranes; $\mathrm{NF} / \mathrm{RO}$ membrane; positive displacement pump; P1-3: pressure sensors, p: pressure gauges, F1-2: flow sensors, V1: pressure relief valve, V2: pressure control valve, PV: photovoltaic array, GPS: solar tracker guided by global positioning system, and MPPT: maximum power point tracker.

Figure 3 (left) Flux and (right) recovery - both as a function of pressure at different feed flows ( $300 \mathrm{~L} / \mathrm{h},-400 \mathrm{~L} / \mathrm{h},{ }^{7} 500 \mathrm{~L} / \mathrm{h}$ ) for four membranes (BW30, ESPA4, NF90, and TFC-S)

Figure 4 (left) Permeate conductivity compared to ADWG (horizontal line) and (right) Retention of conductivity as a function of pressure at different feed flows (:300 L/h, $-400 \mathrm{~L} / \mathrm{h}$, $7500 \mathrm{~L} / \mathrm{h}$ ) for four membranes (BW30, ESPA4, NF90, and TFC-S) and retention required to meet the ADWG for TDS removal (horizontal line) (18).

Figure 5 (left) Specific energy consumption (SEC) and (right) concentrate conductivity as a function of pressure at different feed flows $(: 300 \mathrm{~L} / \mathrm{h},-400 \mathrm{~L} / \mathrm{h}, 7500 \mathrm{~L} / \mathrm{h})$ for four different membranes (BW30, ESPA4, NF90, and TFC-S). Also plotted is the feed wate conductivity $(8290 \mu \mathrm{S} / \mathrm{cm})$ and the maximum conductivities for using the concentrate for sheep (top; $21800 \mu \mathrm{S} / \mathrm{cm}$ ) and beef (bottom; $8800 \mu \mathrm{S} / \mathrm{cm}$ ) cattle stock watering in a mainaining condition function (as opposed to the lower value for healthy growth) (26). 
Schäfer, A.I. ; Broeckmann, A. ; Richards, B.S. (2007) Renewable energy powered membrane technology. 1. Development and characterisation of a photovoltaic hybrid membrane system, Environmental Science \& Technology, 41, 998-1003.

DOI: 10.1021/es061166o

Figure 1

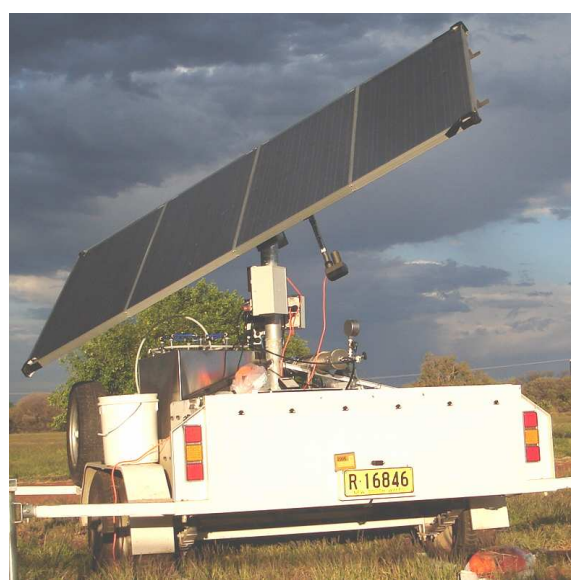

Figure 2

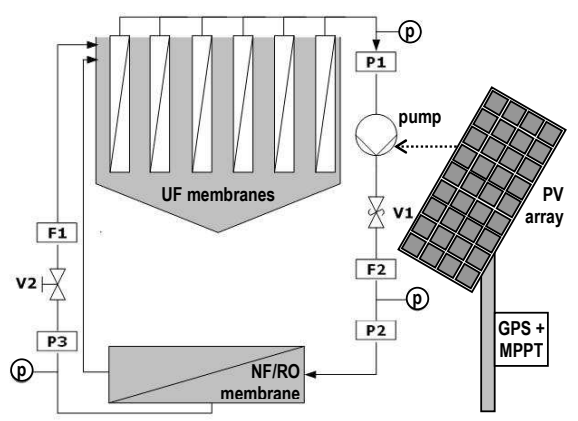


Schäfer, A.I. ; Broeckmann, A. ; Richards, B.S. (2007) Renewable energy powered membrane technology. 1. Development and characterisation of a photovoltaic hybrid membrane system,

Environmental Science \& Technology, 41, 998-1003.

DOI: 10.1021/es061166o

Figure 3

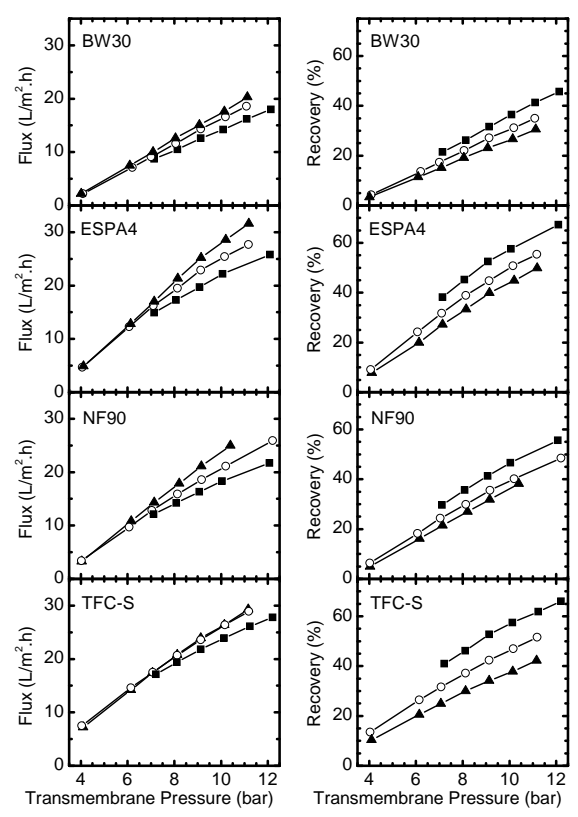

Figure 4

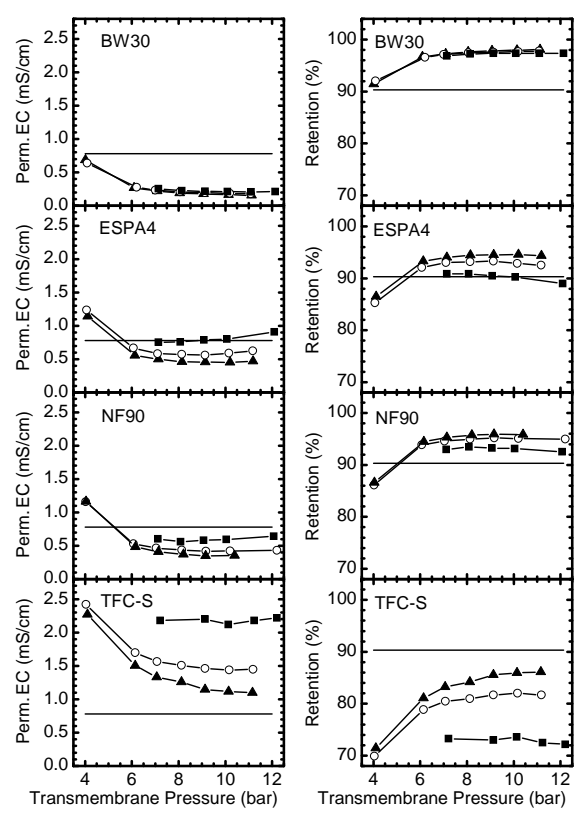


Schäfer, A.I. ; Broeckmann, A. ; Richards, B.S. (2007) Renewable energy powered membrane technology. 1. Development and characterisation of a photovoltaic hybrid membrane system,

Environmental Science \& Technology, 41, 998-1003.

DOI: $10.1021 / \mathrm{es} 061166$ o

\section{Figure 5}

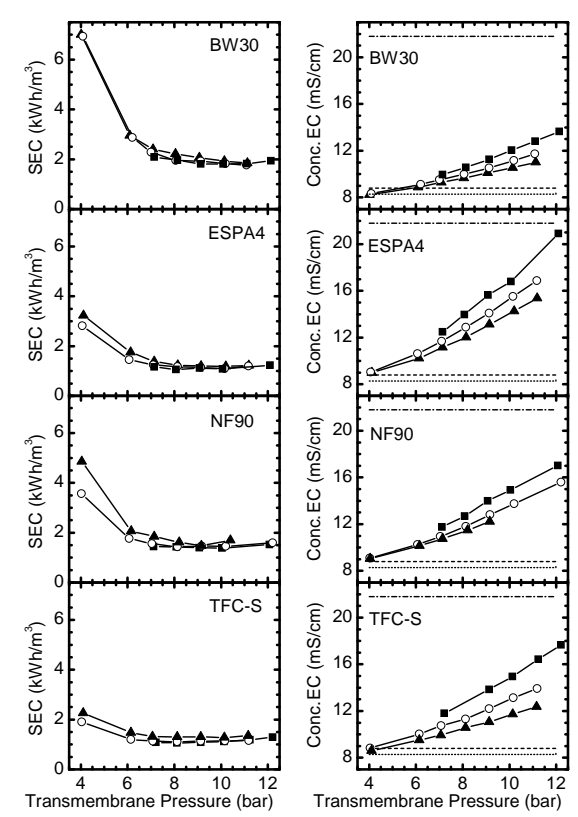

Table 1: Water analysis results of selected contaminants of interest for bore (RN 13693) at the Pine Hill Station. The Australian Drinking Water Guideline (ADWG) upper limit for some elements is listed in the last column (18).

\begin{tabular}{l|l|l|l}
\hline \multicolumn{1}{c|}{ Element } & Unit & Pine Hill Station & $\begin{array}{c}\text { ADWG } \\
(18)\end{array}$ \\
\hline \hline Arsenic & $\mathrm{mg} / \mathrm{L}$ & 0.00613 & 0.007 \\
\hline Barium & $\mathrm{mg} / \mathrm{L}$ & 0.021 & 0.7 \\
\hline Boron & $\mathrm{mg} / \mathrm{L}$ & 0.528 & 4 \\
\hline Calcium & $\mathrm{mg} / \mathrm{L}$ & 101.5 & - \\
\hline Magnesium & $\mathrm{mg} / \mathrm{L}$ & 135.7 & - \\
\hline Manganese & $\mathrm{mg} / \mathrm{L}$ & 0.11 & 0.5 \\
\hline Potassium & $\mathrm{mg} / \mathrm{L}$ & 13.1 & - \\
\hline Sodium & $\mathrm{mg} / \mathrm{L}$ & 1341 & - \\
\hline Silica & $\mathrm{mg} / \mathrm{L}$ & 28 & - \\
\hline Sulphate & $\mathrm{mg} / \mathrm{L}$ & 848.8 & 500 \\
\hline Selenium & $\mathrm{mg} / \mathrm{L}$ & 0.028 & 0.01 \\
\hline Uranium & $\mathrm{mg} / \mathrm{L}$ & 0.584 & 0.02 \\
\hline TDS & $\mathrm{mg} / \mathrm{L}$ & $5300^{\mathrm{a}, \mathrm{b}}$ & 500 \\
\hline Conductivity $(\mathrm{EC})$ & $\mu \mathrm{S} / \mathrm{cm}$ & $8290^{\mathrm{b}}$ & $780^{\mathrm{a}}$ \\
\hline \hline
\end{tabular}

${ }^{a}$ Calculated using TDS $=0.64 \mathrm{EC}$ (17).

${ }^{a}$ Calculated using TDS $=0.64 \mathrm{EC}(17)$.
${ }^{b}$ Average of feed conductivity throughout field testing at Pine Hill Station. 